\title{
Effects of a Solar Eclipse on the Propagation of VLF-LF Signals: Observations and Results
}

\author{
Barin Kumar De ${ }^{1}$, Syam Sundar De ${ }^{2, *}$, Bijoy Bandyopadhyay ${ }^{2}$, Pinaki Pal ${ }^{1,3}$, Rousan $\mathrm{Ali}^{1,4}$, \\ Suman Paul ${ }^{2}$, and Prabir Kanta Goswami ${ }^{2}$ \\ ${ }^{1}$ Department of Physics, University of Tripura, Suryamaninagar, Tripura West, India \\ ${ }^{2}$ Centre of Advanced Study in Radiophysics \& Electronics, University of Calcutta, Kolkata, India \\ ${ }^{3}$ Department of Physics, Maharaja Bir Bikram College, Agartala, Tripura, India \\ ${ }^{4}$ Netaji Subhash Mahavidyalaya, Udaypur, Tripura, India
}

Received 11 September 2010, accepted 17 January 2011

\begin{abstract}
The results from the measurements of some of the fundamental parameters (amplitude of sferics and transmitted signal, conductivity of lower ionosphere) of the ionospheric responses to the 22 July 2009 solar eclipse (partial: 91.7\%) are shown. This study summarizes our results from sferics signals at $81 \mathrm{kHz}$ and subionospheric transmitted signals at $19.8 \mathrm{and} 40 \mathrm{kHz}$ recorded at Agartala, Tripura (latitude: $23^{\circ} \mathrm{N}$, longitude: $91.4^{\circ} \mathrm{E}$ ). We observed significant absorption in amplitude of these signals during the eclipse period compared to their ambient values for the same period during the adjacent 7 days. The signal strength along their propagation paths was controlled by the eclipse associated decrease in ionization in the D-region of the ionosphere. Waveguide mode theory calculations show that the elevation of the height of lower ionosphere boundary of the Earth-ionosphere waveguide to a value where the conductivity parameter was $10^{6}$ unit. The absorption in $81 \mathrm{kHz}$ sferics amplitude is high compared to the absorption in the amplitude of $40 \mathrm{kHz}$ signal transmitted from Japan. The simultaneous changes in the amplitudes of sferics and in the amplitude of transmitted signals assert some sort of coupling between the upper atmosphere and the Earth's near-surface atmosphere prevailing clouds during solar eclipse.
\end{abstract}

Key words: Solar eclipse, Earth-ionosphere waveguide, VLF propagation, Subionospheric transmitted signal

Citation: De, B. K., S. S. De, B. Bandyopadhyay, P. Pal, R. Ali, S. Paul, and P. K. Goswami, 2011: Effects of a solar eclipse on the propagation of VLF-LF signals: Observations and results. Terr. Atmos. Ocean. Sci., 22, 435-442, doi: 10.3319/TAO.2011.01.17.01(AA)

\section{INTRODUCTION}

The cavity between the Earth's surface and lower ionosphere acts as the spherical waveguide in which VLF sferics (electromagnetic waves generated by lightning strokes) and signals from different stations propagate throughout the globe with little attenuation. Global thunderstorm activity, solar radiation, geomagnetic activity, meteor showers directly affect the amplitudes of sferics as well as amplitude and phase of the transmitted signals. The quasi-static electric field observed near the Earth's surface, i.e., Fair Weather Field (FWF), is maintained by global thunderstorm activities (Bering et al. 1998; Rycroft et al. 2000).

Very low frequency (VLF) and low frequency (LF) signals exhibit diurnal and seasonal behaviour upon which

\footnotetext{
* Corresponding author

E-mail:de_syam_sundar@yahoo.co.in
}

signatures of geophysical events such as solar flares, sunspot activity, earthquakes, cyclones, meteor showers, magnetic activities, nuclear explosions are superimposed. The amplitude of sferics is directly affected by global thunderstorm activities (Dixit et al. 1980; Nickolaenko 1997; Rycroft and Cho 1998).

Diurnal behaviour of VLF signals over long distances (>5000 km) was first observed by Yokoyama and Tanimura (1933) and diurnal phase variations by Pierce (1955). Similar experiment was performed by Crombie et al. (1958) and Crombie (1964). These experiments showed good correlation between phase and amplitude variations during sunrise and sunset transitions. Later on, VLF-LF amplitude measurements were done by various authors along different paths (Thomson 1993; McRae and Thomson 2000; Žigman et al. 2007). 
Solar eclipses are known to produce electron density variations in the lower ionosphere. The change in height of the D-region during a solar eclipse is followed by amplitude variations of the VLF-LF signals propagated through the Earth-ionosphere waveguide. Meisel et al. (1976) described a multifrequency oblique-incidence experiment performed during the total solar eclipse of 10 July 1972. They observed a correlation among VLF phase, HF signal strength and geomagnetic field.

Other research has focused on the effects of solar eclipse on VLF signal amplitude and their phase changes along different paths of variable distance and orientations (Kaufmann and Schaal 1968; Dixit et al. 1980; Pant and Mahra 1994; Clilverd et al. 2001). The changes in the ionospheric height and ionization jointly affect the amplitude and phase of the transmitted signal.

The effects of solar eclipse on meteorological parameters are important to study the responses of the atmosphere under the specific conditions of the abrupt changes of incident solar radiations. The variables to consider might include air and soil temperatures, solar irradiance, humidity, wind speed and wind directions. Significant changes occur in the main meteorological parameters at the surface layer associated with the eclipse event (Anderson 1999; Hanna 2000; Zerefos et al. 2001; Aplin and Harrison 2003). Szałowski (2002) worked on the changes of heat and momentum fluxes within the boundary layer during the eclipse. The magnitude of the variations are dependent on the place of observation, the season and time of the day, the climatic conditions and the percentage of the Sun's coverage during the eclipse (Fernández et al. 1993; Founda et al. 2007).

Various authors have reported disturbances in the ionosphere during solar eclipse in terms of changes in VLFLF amplitude of transmitted signals (Kaufman and Schaal 1968; Pant and Mahra 1994; De and Sarkar 1997a; Clilverd et al. 2001). The change in ionospheric height and removal of electrons jointly affect the sferics amplitude and signal amplitude. Dixit et al. (1980) noted an enhancement of field strength at $164 \mathrm{kHz}$. The maximum enhancement occurred a little after the total obscuration. They attributed the result as a consequence of decrease in ionization in the D-region and increase in the reflection height.

Lynn (1981) reported results of VLF transmissions at 13.6 and $22.3 \mathrm{kHz}$ from Omega Reunion, Omega, Japan and NWC, received at Melbourne during the total solar eclipse of 23 October 1976. The phase response was found to be a non-linear function of solar obscuration with a maximum phase deviation which was less than expected when compared with the normal diurnal phase variation. The time constant of ionospheric response was found to be four minutes. Costa et al. (1995) received VLF radio signals $(12.9 \mathrm{kHz})$ at Atibaia, Brazil (latitude: $23.18^{\circ} \mathrm{S}$, longitude: $46.55^{\circ} \mathrm{W}$ ) transmitted from $\Omega$-Argentina (latitude: $43.2^{\circ} \mathrm{S}$, longitude: $65.4^{\circ} \mathrm{W}$ ) during the total solar eclipse of 30 June 1992 . The surface path of the totality crossed the VLF propagation path during the sunrise transition period. The eclipse produced a phase delay of $6.4 \mu \mathrm{s}$ and an amplitude change of $1.3 \mathrm{~dB}$. So to say, various authors (Crary and Schneible 1965; Reeve and Rycroft 1972; Sen Gupta et al. 1980; Lynn 1981; Mendes Da Costa et al. 1995) reported the solar eclipse effects were to be path and frequency dependent. Experimental measurements of the ionospheric parameters at the time of solar eclipses are needed to understand the behaviour and characteristics of the ionosphere (Buckmaster and Hansen 1986; Zeng et al. 1997; Clilverd et al. 2001; Sanders 2001; Founda et al. 2007). A survey of the VLF-LF spectrum evolution was conducted by Fleury and LassudrieDuchesne (2000) in the vicinity of the totality region during the solar eclipse of 11 August 1999. The measurements consisted of amplitude in the frequency range $10-80 \mathrm{kHz}$ using various transmitters during both the eclipse day and the control days. The time signatures of the eclipse appear to be remarkably uncertain according to the frequency and radio path characteristics.

Continuous monitoring of VLF sferics at $81 \mathrm{kHz}$, and subionospheric signals at $19.8 \mathrm{kHz}$ transmitted from North West Cape, Australia $\left(21.82^{\circ} \mathrm{S}, 114.16^{\circ} \mathrm{E}\right)$ and $40 \mathrm{kHz}$ from Japan $\left(36.18^{\circ} \mathrm{N}, 139.85^{\circ} \mathrm{E}\right)$ are being conducted at Agartala, Tripura $\left(23^{\circ} \mathrm{N}, 91.4^{\circ} \mathrm{E}\right)$. The effects of perturbation in the Earth-ionosphere waveguide due to this solar eclipse on the amplitudes of these signals have been measured. The objective of this study was to investigate the variation in amplitude of sub-ionospheric transmitted VLF signals and sferics due to the solar eclipse of 22 July 2009.

\section{INSTRUMENTATION}

The recording system consisted of a loop antenna feeding a number of OP-AMPs which are generally used in tuned radio frequency modes. To ensure high selectivity, the induction coil was mounted inside a pot-core of ferrite material. The signal from the tuning stage was fed to an $\mathrm{AC}$ amplifier using OP- AMP IC531 in a non-inverting mode. The AC signal was then passed to the input of a detector circuit through a unit gain buffer using OP-AMP IC531. In the detector circuit, a diode OA79 was used in the negative rectifying mode. The output of the rectifier is obtained across a parallel combination of resistance and capacitance. The level of the detected envelope is proportional to the RMS value of the AC signal. The detected RMS output is amplified by a quasi-logarithmic amplifier using OP-AMP 741 in the DC mode. The recording time constant of RMS value is $15 \mathrm{sec}$. The calibration of the recording system was carried out using a standard signal generator. During calibration, the antenna was disconnected and replaced by the standard signal generator using a capacitance having its value equal to the terminal capacitance of the antenna. At first, the outputs are calibrated in terms of RMS value of induced voltages at the 
antenna. To get very low signals from the function generator, a dB-attenuator was used. The data in the form of RMS value were recorded by digital technique using a data acquisition system with a PCI 1050, 16 channel 12 bit DAS card (Dynalog). It has a 12 bit A/D converter, 16 digital input and 16 digital outputs. The input multiplexer has a built-in over-voltage protection arrangement. All the I/O parts are accessed by 32 bit I/O instructor, thereby increasing the data input rate. It is supported by a 32-bit API, which functions for I/O processing under the Win 98/2000 operating system. The antenna system for recording LF sferics consisted of an inverted L-type thick wire to receive vertically polarized sferics in the omni-directional pattern from the near and far sources. The effective height was fixed to $8.63 \mathrm{~m}$. The terminal capacitance of the antenna wire was kept at $694 \mathrm{pF}$. Data were recorded at a sample rate of 10 data per sec using computer sound card and analyzed with Origin LAB 7.0.

\section{OBSERVATIONS AND ANALYSES}

On 22 July 2009, the eclipse began at 05:29.5 hr IST and continued until 07:34.9 hr IST. From Agartala 91.7\% occultation was observed during maximum phase. Local sunrise and sunset times were 04:50 hr IST and 18:12 hr IST, respectively. The temperature was $27.3^{\circ} \mathrm{C}$ at the start of the eclipse which reached the minimum value $24.2^{\circ} \mathrm{C}$ at the maximum phase of the eclipse which occurred at 06:28.5 hr IST. The relative humidity was $81.5 \%$ at the time of start and changed to $92.6 \%$ at the time of the greatest phase. The eclipse of 22 July 2009 was visible as a total solar eclipse from Indore, in the Western part of India to Dibrugarh, the Eastern part of India. The minimum distance of Agartala from the path of totality was about $350 \mathrm{~km}$. The geometry of the propagation path of $19.8 \mathrm{kHz}$ from North West Cape, Australia to Agartala and $40 \mathrm{kHz}$ signal from Japan are shown by the lines $\mathrm{AB}$ and $\mathrm{AC}$, respectively in Fig. 1. The path of totality is shown by the line PQ. The great circle distances of these two transmitting stations from the receiving station are about 5670 and $4855 \mathrm{~km}$, respectively.

A rapid decrease in amplitude occurred before the eclipse whereas a rapid increase took place after the eclipse. The temporal variation of the amplitude of $19.8 \mathrm{kHz}$ signal on 22 July 2009 (continuous line curve) together with its normal trend obtained from the average of 7 days adjacent to the day of occurrence of solar eclipse (dashed line curve) are shown in Fig. 2. The period 7 days consists of \pm 3.5 days on either end of the day of occurrence of the eclipse. Standard deviations are denoted by error bars. The amplitude (in arbitrary units) started to decrease from about 04:00 hr IST and continued to show a low value during the period of eclipse. After the eclipse had been completed, the amplitude started to increase gradually from about 07:30 hr IST. Within this period, the curve showed a $\mathrm{W}$-shaped variation. The average of the zigzag minimum value of the amplitude was
$475 \mathrm{AU}$ during the period of eclipse, whereas the minimum level of average diurnal graph was around $1000 \mathrm{AU}$. The extra decrease in amplitude during the maximum obscuration was about $6.4 \mathrm{~dB}$. Then the level started to increase and showed the average trend up to local midnight with level slightly smaller than the average value.

Figure 3 shows the variation of the amplitude of $40 \mathrm{kHz}$ subionospheric transmitted signal. The nature of variation was almost same as that of the $19.8 \mathrm{kHz}$ signal. The average of the zigzag minimum value of the amplitude is $980 \mathrm{AU}$ during the period of eclipse, whereas the minimum level of average diurnal graph was around $1320 \mathrm{AU}$. The fall in amplitude of $40 \mathrm{kHz}$ signal was about $2.6 \mathrm{~dB}$ during the maximum obscuration.

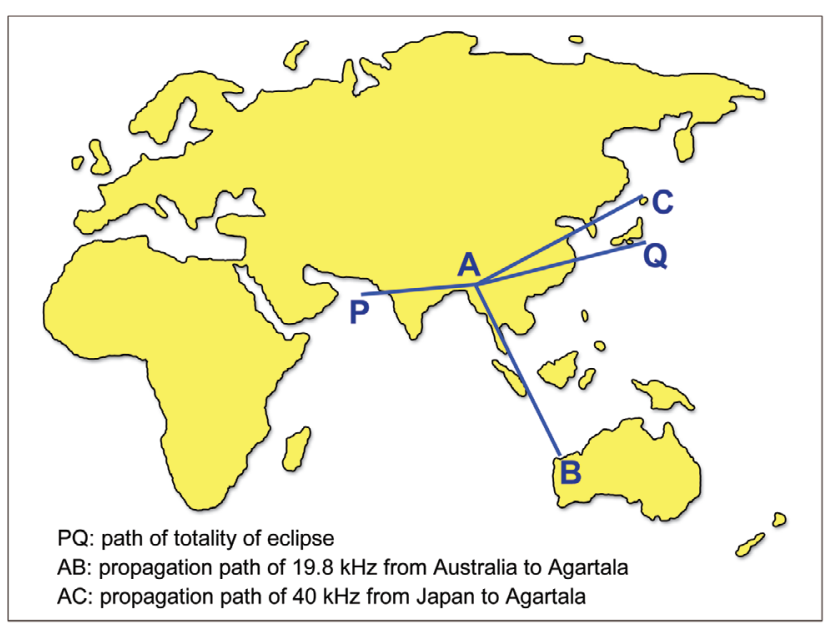

Fig. 1. The propagation path of $19.8 \mathrm{kHz}$ subionospheric signal from Australia to Agartala and of $40 \mathrm{kHz}$ from Japan are shown as lines AB and $\mathrm{AC}$ respectively. $\mathrm{PQ}$ is the path of totality.

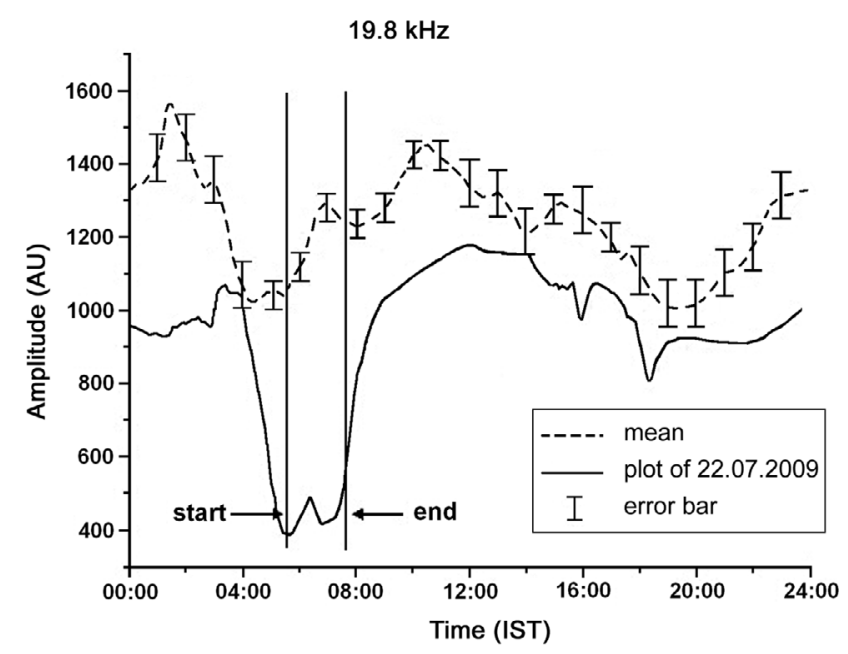

Fig. 2. Variation of $19.8 \mathrm{kHz}$ subionospheric signal amplitude, transmitted from North West Cape, Australia $\left(21.82^{\circ} \mathrm{S}, 114.16^{\circ} \mathrm{E}\right)$ during the period of eclipse (continuous line). The dash line curve depicts the average of adjacent 7 days. Error bars indicate standard deviations. 


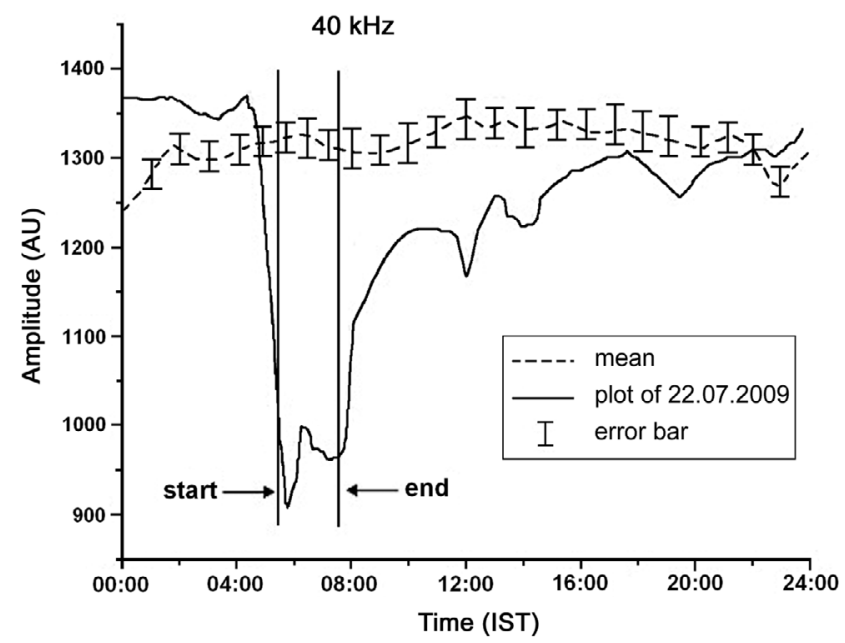

Fig. 3. Variation of $40 \mathrm{kHz}$ subionospheric signal amplitude, transmitted from Japan $\left(36.18^{\circ} \mathrm{N}, 139.85^{\circ} \mathrm{E}\right)$ during the period of eclipse. The continuous line indicates the amplitude. The dash line indicates the average of adjacent 7 control days. Error bars indicate standard deviations.

The variation of amplitude of $81 \mathrm{kHz}$ sferics has been presented in Fig. 4. The level of sferics started to decrease at 05:00 hr IST. Then the sferics showed a minimum at about 06:00 hr IST. After that the sferics started to increase and reached its normal value at about 14:00 hr IST. It also showed certain lower values around 12:00 and 19:00 hr IST. The extra-attenuation of sferics at $81 \mathrm{kHz}$ during the maximum obscuration is about $4.6 \mathrm{~dB}$.

\section{DISCUSSION}

The waveguide formed between the lower ionosphere (D-region and Earth's surface) is good for very low frequency (VLF) and low frequency (LF) propagation round the Earth.

The status of the D-layer of the ionosphere is responsible to determine the amount of attenuation to VLF signals. It is also most sensitive to the loss of sunlight during solar eclipse. This is because, it is the lowermost of the layers and is quickly filled by the neutral air around it as soon as the active ionizing source of radiation is removed. However, the E-layer above the D-layer is more resilient to the loss of radiation and persists much longer period, even for a while after the solar eclipse. Due to lack of solar irradiation (the main source of ionization) over the eclipse zone, the ionization process at the D-region height decreases which drives the D-region upwards. As the transmitted signals propagate through the process of multiple reflections within the Earthionosphere waveguide, the effective propagation path of the signal increases in length which is responsible for the observed phase delay of signal.

To explain the sudden fall in signal level, we looked for the effect of modal conversion in waveguide propaga- tion. On both sides of the eclipse track, daylight is present. Due to discontinuity at the boundary of the eclipse track, modal conversion (Lynn 1973, 1981) can occur at VLF. Some energy may be transferred from the first mode to the other modes making the first mode suddenly weaker compared to the initial value.

The attenuation factor $\left(\alpha_{M}\right)$ for the $\mathrm{M}^{\text {th }}$ mode of propagation in the Earth-ionosphere waveguide is given by Yamashita (1969):

$\alpha_{\mathrm{M}}=-8.68 \times(2 \pi / \lambda) \times \operatorname{Im}\left(\mathrm{S}_{\mathrm{M}}\right) \mathrm{dB} \mathrm{km}^{-1}$

where $S_{M}=\left(1-C_{M}^{2}\right)^{1 / 2}, C_{M}$ being the root of the modal equation given by

$\mathrm{R}_{\mathrm{i}} \exp \left(\mathrm{ik}_{0} \mathrm{hC}_{\mathrm{M}}\right)=\exp (-\mathrm{i} 2 \pi \mathrm{M})$

where $\mathrm{h}=$ height of the boundary of the ionosphere.

The Fresnel's reflection coefficient $\mathrm{R}_{\mathrm{i}}$ of the lower boundary of the ionosphere is given by Yamashita (1969):

$R_{i}=\frac{\left(1-\frac{\omega_{r}}{\omega}\right)^{2} C_{M}-\left[\left(1-i \frac{\omega_{r}}{\omega}\right)^{2}-S_{M}^{2}\right]^{1 / 2}}{\left(1-i \frac{\omega_{r}}{\omega}\right)^{2} C_{M}+\left[\left(1-i \frac{\omega_{r}}{\omega}\right)^{2}-S_{M}^{2}\right]^{1 / 2}}$

The conductivity parameter, $\omega_{\mathrm{r}}=\omega_{0}^{2} / \nu, \omega_{0}$ is the angular plasma frequency, and $v$ is the collision frequency.

The conductivity parameter as mentioned in the waveguide mode theory is given by (Wait and Spices 1964):

$\omega_{\mathrm{r}}=2.5 \times 10^{5} \exp \left[\beta\left(\mathrm{h}-\mathrm{H}^{\prime}\right)\right]$

$\beta=0.43 \mathrm{~km}^{-1}$ and $\mathrm{H}^{\prime}=72 \mathrm{~km}$, since they are appropriate for normal ionosphere (Thomson 1993). During solar eclipse, $\beta$ may be increased to $0.5 \mathrm{~km}^{-1}$ (Clilverd et al. 2001) and $\mathrm{H}^{\prime}$ to $75.75 \mathrm{~km}$.

The parameters $\beta$ and $\mathrm{H}^{\prime}$ jointly determine the conductivity parameter and hence the attenuation factor during solar eclipse. In the shadow region, the variation of electron density above $80 \mathrm{~km}$ is negligible (Verronen et al. 2006). On the other hand, below $72 \mathrm{~km}$, the decrease in electron density during eclipse is high. Therefore the absorption of VLF and LF radio waves decreases during eclipse showing changes in amplitude.

Using Eqs. (2) and (3) in Eq. (1), the variation of attenuation factor $\alpha$ (in $\mathrm{dB}$ per $1000 \mathrm{~km}$ for the first mode at $\mathrm{M}=1$ ) with $\omega_{\mathrm{r}}$ is obtained. The variation for the first mode which is dominant in the case of long distance propagation is shown in Figs. 5a and b at the frequencies of 19.8 and $40 \mathrm{kHz}$. At $19.8 \mathrm{kHz}$, the value of attenuation corresponding to the normal value of $\omega_{\mathrm{r}}\left(=2.5 \times 10^{5}\right)$ is $1.76 \mathrm{~dB}$ per 


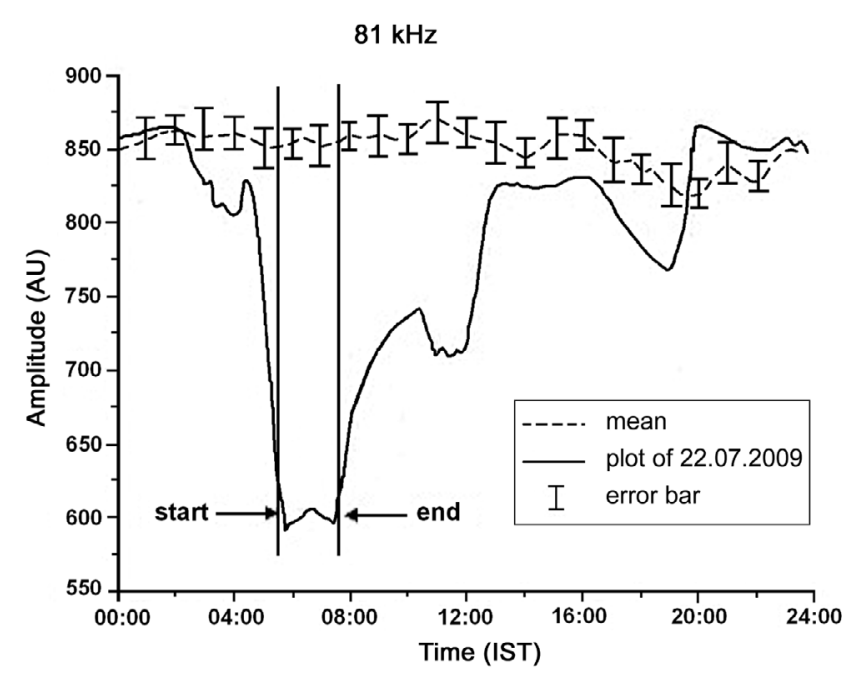

Fig. 4. $81 \mathrm{kHz}$ sferics signal amplitude fluctuations during the period of eclipse. The line indicates the amplitude. The dashed line indicates the average for adjacent 7 days. Error bars indicate standard deviations.

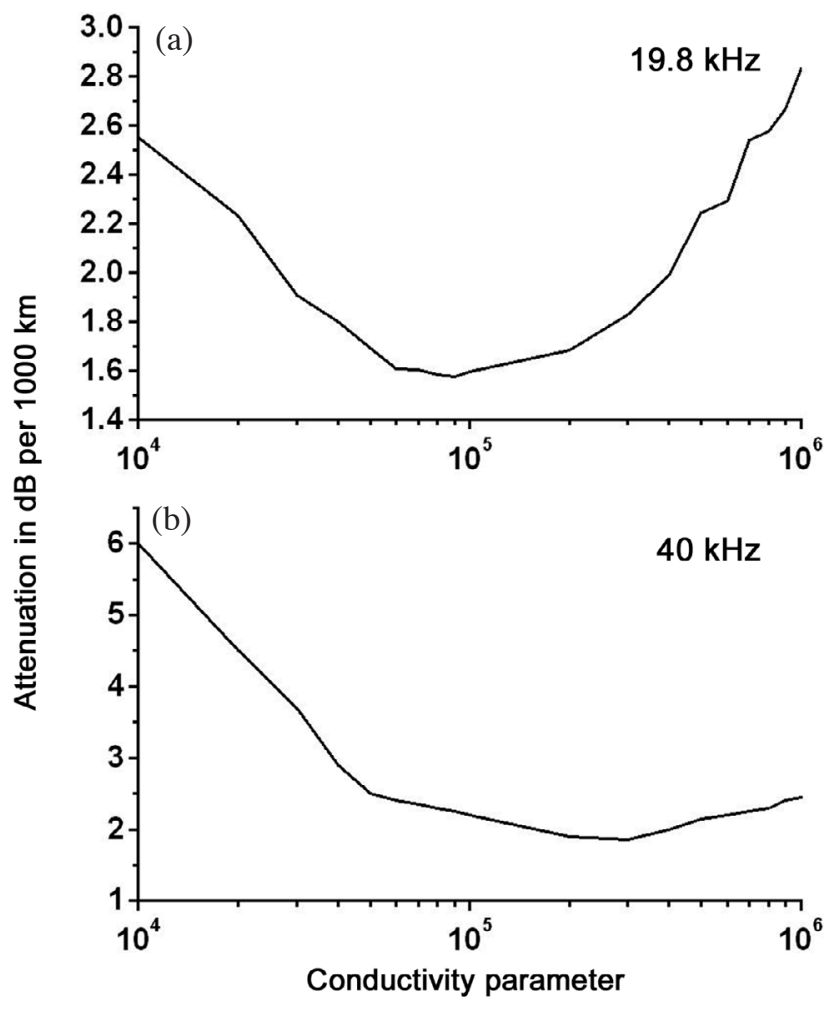

Fig. 5. Variation of attenuation in $\mathrm{dB}$ per $1000 \mathrm{~km}$ at 19.8 and $40 \mathrm{kHz}$.

$1000 \mathrm{~km}$. From the observation of phase delay, it is confirmed that reflection height of the VLF signal would be increased (Kaufmann and Schaal 1968; Dixit et al. 1980; Pant and Mahra 1994; Clilverd et al. 2001). According to Eq. (3), the signals get reflected from the height at which $\omega_{\mathrm{r}}$ would be higher than the normal value. It shows the increase of attenuation by $6.4 \mathrm{~dB}$ over a path of $5670 \mathrm{~km}$, which gives the additional attenuation of $1.1 \mathrm{~dB}$ per $1000 \mathrm{~km}$. The total attenuation then becomes $(1.76+1.1)=2.86 \mathrm{~dB}$ per $1000 \mathrm{~km}$. From Fig. 5a, this attenuation corresponds to $\omega_{\mathrm{r}}$ $=10^{6} \mathrm{sec}^{-1}$.

At $40 \mathrm{kHz}$, the value of attenuation corresponding to the normal value of $\omega_{\mathrm{r}}\left(=2.5 \times 10^{5}\right)$ is $2 \mathrm{~dB}$ per $1000 \mathrm{~km}$. The present observation showed the increase of attenuation by $2.6 \mathrm{~dB}$ over a path of $4855 \mathrm{~km}$ which makes an additional attenuation of $0.54 \mathrm{~dB}$ per $1000 \mathrm{~km}$. The total attenuation then becomes $(2+0.54)=2.54 \mathrm{~dB}$ per $1000 \mathrm{~km}$. From Fig. $5 b$, this attenuation corresponds to $\omega_{\mathrm{r}}=1.05 \times 10^{6} \mathrm{sec}^{-1}$. So, the observational results at 19.8 and $40 \mathrm{kHz}$ provide almost same value of conductivity parameter for the reflection of VLF and LF radio waves during solar eclipse.

Although a solar eclipse primarily is of astronomical interest, meteorological changes also result from the abrupt change in insolation, causing cooling in the surface layers of the atmosphere and damping of atmospheric turbulence from the surface upwards (Aplin and Harrison 2003). In our study, the changes were found to be relatively slow throughout the partial phases of the eclipse.

The occurrence of solar eclipse has its effects locally and widely over different levels of terrestrial lower atmosphere, ionosphere and the magnetosphere. The changes of ionization in the lower ionosphere during the eclipse lead to the perturbations in electron density and electrical conductivity (Karunakaran 1997; Sanders 2001). Thus, solar eclipses produce disturbances in the ionosphere, which cause noticeable effects on low frequency wave propagation. All observations show distinctive changes in signal strengths around the times when a solar eclipse would be crossing the propagation path between the observation point and the transmitter position of the subionospheric signals. Thus, solar eclipses are important events to ionospheric physicists, because these render an opportunity to study the dynamical responses of the ionosphere toward the variation of the solar radiation.

On 22 July 2009, there was a continuation of a principal geomagnetic storm commenced on 20 July and ended on 25 July 2009. Effects of the storm can be discarded based on the following:

Earlier studies reported that during and after geomagnetic storms, the daytime level becomes greater than the nighttime level (De and Sarkar 1994, 1995a). This kind of effect can persist for several days after geomagnetic storms. During geomagnetic storm, the post-sunset maximum (PSM) can disappear in the case of long distance signal (De and Sarkar 1995b). During geomagnetic storm, the afternoon maxima (AMX) in the case of long distance signal amplitude was also found to be absent (De and Sarkar 1997b). A significant test showed a high correlation of the absence of AMX with geomagnetic storms. Correia et al. (2007) analyzed the occurrence of VLF events in the form of fast amplitude variations in association with geomagnetic storms. 
In fact, they reported that VLF events occurred in higher number during recovery phase of geomagnetic storms. Peter et al. (2006) examined the effects of two geomagnetic storms on the midlatitude D-region using several VLF signal paths in both the northern and southern hemispheres. The amplitude and phase of the VLF signals exhibited perturbations with increased geomagnetic activity and with fluctuations in amplitude persisting several hours after the occurrence of the geomagnetic storm. They examined the location and timing of the disturbance using multiple VLF signal paths and auroral activity patterns based on auroral flux measurements obtained by the NOAA-POES satellites. The depression and variation of the VLF signal amplitude are shown to be consistent with the measured variations in the energetic electron precipitation flux as recorded by the NOAA-POES satellite.

The paper of Peter et al. (2006) demonstrates that subionospheric VLF signals can be used as a diagnostic of high-energy auroral precipitation at midlatitudes during disturbed geomagnetic conditions. The onset of fluctuations in the VLF amplitude data occurred immediately after the depression of the signal amplitude. It is worth-mentioning that the morphological structure of variations of VLF amplitude during the geomagnetic storms is completely different from our observations during the occurrence of solar eclipse.

A detailed report of geomagnetic storm was presented by the Hyderabad station (Solar Geophysical Data Book NOAA). The commencement time was 07:26 hr IST (02:00 hr UT) on 20 July 2009 and the storm ended at 05:26 hr IST (00:00 hr UT) on 25 July 2009, whereas the solar eclipse started at 05:29.5 hr IST and continued upto 07:34.9 hr IST 22 July 2009 , i.e., the eclipse occurred almost during the mid-period of the storm. But the storm was not strong enough because it was not detected by other stations on the globe. The variation of $\mathrm{H}$ was only $38 \mathrm{Gama}$. The 3-hour value of Kp index during the eclipse was only 3 . According to Table 1, this is an unsettled storm condition. The maximum value of $\mathrm{Kp}$ index observed on 22 July 2009 was 6 , which could be given a status of moderate storm as shown in Table 1. This maximum value of Kp occurred between 08:26 hr IST (03:00 hr UT) and 11:26 hr IST (09:00 hr UT), well after the solar eclipse on 22 July 2009 . The daily in$\operatorname{dex} A p=25$ was also low. So it was a local type moderate storm. We thus nullify the consideration of this storm. It is worth-mentioning that storm duration was about for four days whereas the signal absorption was for the duration of about 2 hours. The duration of signal absorption had a good agreement with the duration of the solar eclipse. The absorption in signal amplitude is thus attributed to the changes in the ionospheric reflection height and the electron density variation during the solar eclipse. However, it is noted that there is difference between ambient level in the eclipse day and average of the other days. This difference might have been controlled by the geomagnetic storms.
The $19.8 \mathrm{kHz}$ signal is a trans-equatorial signal making small angles with the Earth's magnetic field lines of induction. But the propagation of the $40 \mathrm{kHz}$ signal from Japan to Agartala is almost along East-West. The additional attenuation during the eclipse for $19.8 \mathrm{kHz}$ signal is $1.1 \mathrm{~dB}$ per $1000 \mathrm{~km}$ and for $40 \mathrm{kHz}$ signal $0.54 \mathrm{~dB}$ per $1000 \mathrm{~km}$, respectively. This difference may be due to the difference in the precipitation of charged particles over the two propagation paths during geomagnetic storms on 22 July 2009, because the average latitudinal value is higher in magnitude in the case of the Japan-Agartala path than the NWC-Agartala path.

The attenuation in the fall of level in $81 \mathrm{kHz}$ sferics is high compared to that of the amplitude of $40 \mathrm{kHz}$ signal transmitted from Japan. The effects of solar eclipse on meteorological variables like air and soil temperature, solar irradiance, humidity, wind speed, wind directions and others are very much significant (Anderson 1999; Hanna 2000; Zerefos et al. 2001; Aplin and Harrison 2003). Szałowski (2002) investigated the changes of heat and momentum fluxes within the boundary layer during the eclipse. The combined effect of all the variables during solar eclipse may be the reason for the rapid fall of sferics amplitude during the eclipse.

The nature of response of the signals towards the eclipse at these frequencies follows almost the same trend showing a reduction in the value of their amplitudes depending on frequency. Reduction in ionization and elevation of height of the lower ionosphere during the eclipse period are expected to be responsible for such attenuation. The conclusions from our calculations can be summarized:

(1) The decrease in amplitude of the VLF-LF signals was frequency dependent.

(2) The decrease in the signal amplitude during eclipse was due to the decrease in ionization and the elevation of the reflection zone.

Table 1. Kp and Ap indices showing the intensity of magnetic storms.

\begin{tabular}{ccc}
\hline Ap Index & Kp Index & Description \\
\hline 0 & 0 & Quiet \\
4 & 1 & Quiet \\
7 & 2 & Unsettled \\
15 & 3 & Unsettled \\
27 & 4 & Active \\
48 & 5 & Minor storm \\
80 & 6 & Moderate storm \\
132 & 7 & Strong storm \\
208 & 8 & Severe storm \\
400 & 9 & Extreme storm \\
\hline
\end{tabular}


(3) The simultaneous decrease in the amplitudes of sferics and in the amplitude of transmitted signals indicates some sort of coupling mechanism between the ionosphere and the Earth's near-surface atmosphere.

Although the propagation paths were away from its totality, the effects were remarkable. The results presented here resemble the results of earlier experiments carried out during an eclipse.

Acknowledgements The authors gratefully acknowledge the financial support provided by Indian Space Research Organization (ISRO) through S. K. Mitra Centre for Research in Space Environment, University of Calcutta, Kolkata, India for carrying out this work. The authors are also thankful to the respected reviewers for their critical comments and valuable suggestions that helped a lot to improve the revised version.

\section{REFERENCES}

Anderson, J., 1999: Meteorological changes during a solar eclipse. Weather, 54, 207-215.

Aplin, K. L. and R. G. Harrison, 2003: Meteorological effects of the eclipse of 11 August 1999 in cloudy and clear conditions. Proc. R. Soc. Lond. A, 459, 353-371, doi: 10.1098/rspa.2002.1042. [Link]

Bering, E. A. III, A. A. Few, and J. R. Benbrook, 1998: The global electric circuit. Phys. Today, 51, 24-30.

Buckmaster, H. A. and C. H. Hansen, 1986: 26 February 1979 total solar eclipse induced LF $(60 \mathrm{kHz})$ phase retardation. J. Atmos. Terr. Phys., 48, 393-397, doi: 10. 1016/0021-9169(86)90007-3. [Link]

Clilverd, M. A., C. J. Rodger, N. R. Thomson, J. Lichtenberger, P. Steinbach, P. Cannon, and M. J. Angling, 2001: Total solar eclipse effects on VLF signals: Observations and modeling. Radio Sci., 36, 773-788, doi: 10.1029/2000RS002395. [Link]

Correia, E., J. H. Fernández, and J. P. Raulin, 2007: On the determination of lower ionospheric perturbations detected as fast amplitude variations of VLF signals. Oecol. Bras., 11, 23-28.

Crary, J. H. and D. E. Schneible, 1965: Effect of the solar eclipse of 20 July 1963 on VLF signal propagating over short paths. Radio Sci., 69D, 947-957.

Crombie, D. D., 1964: Periodic fading of VLF signal received over a long path during sunrise and sunset. $J$. Res. Nat. Bur. Stand., 68D, 27-34.

Crombie, D. D., A. H. Allan, and M. Newman, 1958: Phase variation of $16 \mathrm{kc} / \mathrm{s}$ transmission from Rugby as received in New Zealand. Proc. IRE, 105, 301-304.

De, B. K. and S. K. Sarkar, 1994: Anomaly in the long distance $40 \mathrm{kHz}$ radio wave propagation. Indian J. Phys., 23, 272-274.

De, B. K. and S. K. Sarkar, 1995a: Anomalous enhancement in daytime $40-\mathrm{kHz}$ signal amplitude accompanied by geomagnetic storms, earthquakes and meteor showers. Ann. Geophys., 13, 1117-1123, doi: 10.1007/s00585995-1117-5. [Link]

De, B. K. and S. K. Sarkar, 1995b: Some studies on postsunset maximum of a long distance LF signal. Indian J. Phys., 24, 126-130.

De, B. K. and S. K. Sarkar, 1997a: Anomalous behaviour of $22.3 \mathrm{kHz}$ NWC signal during total solar eclipse of October 24, 1995. Kodaikanal Obs. Bull., 13, 205-208.

De, B. K. and S. K. Sarkar, 1997b: Seasonal behaviour of the afternoon maxima of a long distance $40 \mathrm{kHz}$ signal. Studia Geoph. et Geod., 41, 382-390.

Dixit, P. S., P. K. Rao, R. V. Bhonsle, G. Sethia, M. R. Deshpande, and H. Chandra, 1980: Phase and field measurements at VLF, LF and HF during the solar eclipse of February, 1980 - Preliminary results. Bull. Astro. Soc. India., 8, 145-148.

Fernández, W., V. Castro, and H. Hidalgo, 1993: Air temperature and wind changes in Costa Rica during the total solar eclipse of July 11, 1991. Earth Moon Planet., 63, 133-147, doi: 10.1007/BF00575102. [Link]

Fleury, R. and P. Lassudrie-Duchesne, 2000: VLF-LF propagation measurements during the 11 August 1999 solar eclipse. Eighth International Conference on HF Radio Systems and Techniques, (IEE Conf. Publ. No. 474), 391-395.

Founda, D., D. Melas, S. Lykoudis, I. Lisaridis, E. Gerasopoulos, G. Kouvarakis, M. Petrakis, and C. Zerefos, 2007: The effect of the total solar eclipse of 29 March 2006 on meteorological variables in Greece. Atmos. Chem. Phys., 7, 5543-5553, doi: 10.5194/acp-7-55432007. [Link]

Hanna, E., 2000: Meteorological effects of the solar eclipse of 11 August 1999. Weather, 55, 430-446.

Karunakaran, D., 1997: Effect of the solar eclipse of October 24, 1995 on the ionospheric F-region over Kodaikanal. Kodaikanal Obs. Bull., 13, 193-196.

Kaufmann, P. and R. E. Schaal, 1968: The effect of a total solar eclipse on long path VLF transmission. J. Atmos. Terr. Phys., 30, 469-471, doi: 10.1016/0021-9169 (68)90119-0. [Link]

Lynn, K. J. W., 1973: VLF mode conversion observed at middle latitudes. J. Atmos. Terr. Phys., 35, 439-452, doi: 10.1016/0021-9169(73)90035-4. [Link]

Lynn, K. J. W., 1981: The total solar eclipse of 23 October 1976 observed at VLF. J. Atmos. Terr. Phys., 43, 13091316, doi: 10.1016/0021-9169(81)90156-2. [Link]

McRae, W. M. and N. R. Thomson, 2000: VLF phase and amplitude: Daytime ionospheric parameters. J. Atmos. Sol.-Terr. Phys., 62, 609-618, doi: 10.1016/S1364-68 26(00)00027-4. [Link]

Meisel, D. D., B. Duke, R. C. Aguglia, and N. R. Goldblatt, 1976: Solar eclipse effects on HF and VLF propagation. 
J. Atmos. Terr. Phys., 38, 495-502, doi: 10.1016/00219169(76)90006-4. [Link]

Mendes Da Costa, A., N. M. Paes Leme, and L. Rizzo Piazza, 1995: Lower ionosphere effect observed during the 30 June 1992 total solar eclipse. J. Atmos. Terr. Phys., 57, 13-17, doi: 10.1016/0021-9169(93)E0021Z. [Link]

Nickolaenko, A. P., 1997: Modern aspects of Schumann resonance studies. J. Atmos. Sol.-Terr. Phys., 59, 805816, doi: 10.1016/S1364-6826(96)00059-4. [Link]

Pant, P. and H. S. Mahra, 1994: Effect of solar eclipses on VLF propagation. Indian J. Radio Space Phys., 23, 399-402.

Peter, W. B., M. W. Chevalier, and U. S. Inan, 2006: Perturbations of midlatitude subionospheric VLF signals associated with lower ionospheric disturbances during major geomagnetic storms. J. Geophys. Res., 111, A03301, doi: 10.1029/2005JA011346. [Link]

Pierce, J. A., 1955: The diurnal carrier phase variation of 16 $\mathrm{kc} / \mathrm{s}$ transatlantic signal. Proc. IRE, 43, 584-588.

Reeve, C. D. and M. J. Rycroft, 1972: The eclipsed lower ionosphere as investigated by natural very low frequency radio signals. J. Atmos. Terr. Phys., 34, 667672, doi: 10.1016/0021-9169(72)90154-7. [Link]

Rycroft, M. J. and M. Cho, 1998: Modelling electric and magnetic fields due to thunderclouds and lightning from cloud-tops to the ionosphere. J. Atmos. Sol.-Terr. Phys., 60, 889-893, doi: 10.1016/S1364-6826(98)00 037-6. [Link]

Rycroft, M. J., S. Israelsson, and C. Price, 2000: The global atmospheric electric circuit, solar activity and climate change. J. Atmos. Sol.-Terr. Phys., 62, 1563-1576, doi: 10.1016/S1364-6826(00)00112-7. [Link]

Sanders, M., 2001: Solar eclipse effect on the propagation of LF radio signals. available at http://www.xs4all.nl/ $\sim$ misan/eclipse.htm.

Sen Gupta, A., G. K. Goel, and B. S. Mathur, 1980: Effect of the 16 February 1980 solid eclipse on VLF propaga- tion. J. Atmos. Terr. Phys., 42, 907-909, doi: 10.1016/ 0021-9169(80)90107-5. [Link]

Szałowski, K., 2002: The effect of the solar eclipse on the air temperature near the ground. J. Atmos. Sol.-Terr. Phys., 64, 1589-1600, doi: 10.1016/S1364-6826(02)00134-7. [Link]

Thomson, N. R., 1993: Experimental daytime VLF ionospheric parameters. J. Atmos. Terr. Phys., 55, 173-184, doi: 10.1016/0021-9169(93)90122-F. [Link]

Verronen, P. T., Th. Ulich, E. Turunen, and C. J. Rodger, 2006: Sunset transition of negative charge in the Dregion ionosphere during high-ionization conditions. Ann. Geophys., 24, 187-202, doi: 10.5194/angeo-24187-2006. [Link]

Wait, J. R. and K. P. Spices, 1964: Characteristics of the Earth-ionosphere waveguide for VLF radio waves. NBS Tech. Note, US, 300.

Yamashita, M., 1969: The conductivity of lower ionosphere deduced from sudden enhancements of strength (SES) of v.l.f. transmissions. J. Atmos. Terr. Phys., 31, 10491057, doi: 10.1016/0021-9169(69)90104-4. [Link]

Yokoyama, E. and I. Tanimura, 1933: Some long distance transmission phenomena of low frequency wave. Proc. IRE, 21, 263.

Zeng, W., X. Zhang, and Z. Huang, 1997: Ionospheric absorption effects of the solar eclipse of 24 October 1995. Terr. Atmos. Ocean. Sci., 8, 233-237.

Zerefos, C. S., D. S. Balis, P. Zanis, C. Meleti, A. F. Bais, K. Tourpali, D. Melas, I. Ziomas, E. Galani, K. Kourtidis, A. Papayannis, and Z. Gogosheva, 2001: Changes in surface UV solar irradiance and ozone over the Balkans during the eclipse of August 11, 1999. Adv. Space Res., 27, 1955-1963, doi: 10.1016/S0273-1177(01)00279-4. [Link]

Žigman, V., D. Grubor, and D. Šulić, 2007: D-region electron density evaluated from VLF amplitude time delay during X-ray solar flares. J. Atmos. Sol.-Terr. Phys., 69, 775-792, doi: 10.1016/j.jastp.2007.01.012. [Link] 